\title{
Assessment of companies' safety processes maturity in requirements engineering with Uni-REPM SCS
}

\author{
Jéssyka Vilela ${ }^{1}$, Luiz Eduardo G. Martins ${ }^{2}$, Tony Gorschek ${ }^{3}$, Jaelson Castro ${ }^{4}$ \\ ${ }^{1}$ Universidade Federal de Pernambuco (UFPE), Brazil \\ ${ }^{2}$ Universidade Federal de São Paulo (UNIFESP), Brazil \\ ${ }^{3}$ Blekinge Institute of Technology (BTH), Sweden \\ ${ }^{4}$ Universidade Federal de Pernambuco (UFPE), Brazil \\ jffv@cin.ufpe.br, legmartins@unifesp.br, tony.gorschek@bth.se, \\ jbc@cin.ufpe.br
}

\begin{abstract}
Safety is an important quality attribute in the development of safetycritical systems (SCS). This attribute can be achieved by improving safety processes maturity to reduce accidents and safety incidents. In this work, we present a safety module called Uni-REPM SCS for the Uni-REPM maturity model. We describe the methodology used to develop the module, how we built and validated it and further research and possibilities of collaboration.
\end{abstract}

\section{Problem context and Motivation}

Safety is an important quality attribute in many safety-critical domains (Varkoi, 2013) that can be achieved by improving safety processes maturity (VILELA et al., 2020). In this context, hazards related to requirements have been associated with many accidents and safety incidents (LEVESON, 2011). Thus, companies should improve their safety (Vilela et al., 2020) and RE process (Svahnberg et al., 2015) with the purpose of overcome the difficulties they face during the construction of SCS. However, companies lack of a model to guide them on how to apply their efforts systematically to achieve safety goals and to maintain continual improvements in safety implementation; and they face difficulties in establishing priorities to safety actions/practices to be followed.

Considering that the development process is considered as one source of safety risks and aiming to unify the development process and give guidance to companies, we proposed Uni-REPM SCS which is a safety module for Uni-REPM (Universal Requirements Engineering Process Maturity Model) (SVAHNBERG et al., 2015). The latter is a well-established, adopted by companies and a complete RE existing model. Our goal is to Improve the quality of safety requirements engineering process by developing a safety module for Uni-REPM maturity model which is useful and suitable to domainindependent systems in order to increase the safety processes maturity levels and further develop safer systems. Handling safety concerns early in software development contributes to ensure that safety problems do not propagate through subsequent phases (SVAHNBERG et al., 2015). Moreover, high safety levels are typically better achieved by addressing safety from the beginning; not by trying to add protection components and additional complexities after the system has been developed (LEVESON, 2011).

\section{Methodology}

We adopted the design science research which is a well-established methodology used by the literature to propose maturity models. Accordingly, we followed a 9-step 
methodology to construct the Uni-REPM SCS (Vilela et al., 2020): 1. Knowledge Acquisition, 2. Problem definition, 3. Identification of information sources, 4. Definition of module design/architecture, 5. Development of a draft model - process dimension, 6. Development of a draft model - capability/maturity dimension, 7. Consolidate the module, 8. Comparison with existing maturity models, and 9. Module evaluation and refinements. This methodology was defined by considering the engineering design cycle, a technology transfer framework and by adapting methodologies for creating maturity models available in literature that inspired our model.

\section{The Uni-REPM SCS Solution}

The safety module follows Uni-REPM dual-view-approach (Vilela et al., 2020): Process Area view (that defines three levels: Main process area (MPA), Sub-process area (SPA) and Action) and Maturity Level view (with three maturity levels: Basic, Intermediate and Advanced). The MPAs of Uni-REPM, which are the same for Uni-REPM SCS, as well as the 14 safety new sub-process areas of Uni-REPM SCS are presented in Figure 1.

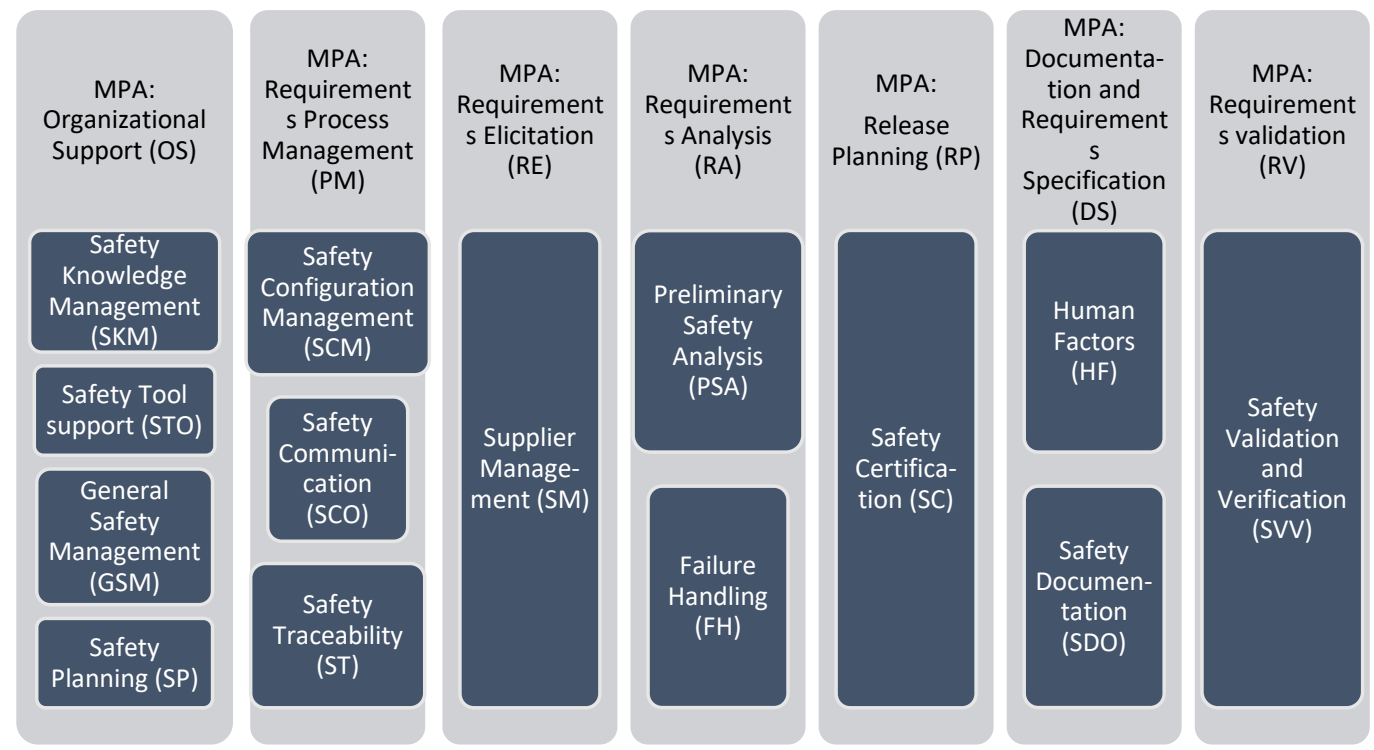

Figure 1. Process (MPA) and subprocess (SPA) areas of Uni-REPM SCS.

At the low-level of module structure, we have "actions" that represent a specific good practice. In Figure 2, we present an example of a safety action. By performing the action, the organization can improve their process and gain certain benefits. The complete description of the safety module and the 148 actions of Uni-REPM SCS can be found in the project website http://www.unirepm.com as well as the tool we developed to perform safety and RE maturity assessments. The tool implements web-based questionnaires (Figure 3) in which an evaluator can select to which action if it is "Incomplete", "Complete" or "Inapplicable" as well as insert additional comments on the action. After answering all questions, the tool determines and presents the evaluation results allowing the visualization of the project maturity level as well the levels reached in each SPA and MPA as well as graphical visualization of the results.

\section{How we built and validated Uni-REPM SCS}

We followed the technology transfer framework to validate Uni-REPM SCS and ensure that the model quality is suitable for companies. First, we performed a static validation 
SCS when it is instantiated in different safety-critical domains; (iv) The module had a good level of acceptance by practitioners; (v) The module lag analysis showed that the module has a good applicability and the proposed safety actions are in fact used by the SCS companies.

\section{Using Uni-REPM SCS}

Uni-REPM SCS is an independent domain safety maturity model, hence, any safety-critical company would benefit from using our proposal. The safety module can be applied to assess both an ongoing product development such as a new one. The companies can evaluate themselves by registering in our website and answering the assessment questionnaire (Figure 3). For now, we only have an English version of Uni-REPM SCS.

We envision some benefits to industry of adopting Uni-REPM SCS: Evaluation regarding specific process areas in which the company may be most interested; Module could be used as a diagnostic tool by enabling the determination of the current state ("asis") of companies processes; The safety maturity evaluation reveals areas of weakness and improvement opportunities; Assessment instrument fully supported by online software tool; Module can be used with any methodology of system development; and, The module could be used in different types of companies.

\section{Next steps/Further Research}

We are open to possibilities of academia-company cooperation including projects to:

- conduct safety evaluations of the companies' processes using the Uni-REPM SCS;

- investigate what is the module impact in the safety processes considering before/after assessments of companies;

- perform software safety improvements projects to make an analysis comparing what are the practical gains for the projects of using this module, taking into account how the projects were before and after using it;

- conduct case studies to explore if practitioners can reconcile the actions in the module with what they already need to do in order to comply with mandatory standards in their application domain;

- do Post-Mortem analysis: assess the safety maturity of ended projects and correlate the maturity levels with the quality of the developed system.

\section{References}

Vilela, J., Castro, J., Martins, L. E. G. and Gorschek, T. (2020) "Safety Practices in Requirements Engineering: The Uni-REPM Safety Module," IEEE Transactions on Software Engineering, vol. 46, no. 3, pp. 222-250.

Leveson, N. Engineering a safer world: Systems thinking applied to safety. Mit Press, 2011.

Svahnberg, M., Gorschek, T., Nguyen, T. T. L., Nguyen, M. (2015). "Uni-repm: a framework for requirements engineering process assessment", Requirements Engineering, Springer, v. 20, n. 1, p. 91-118.

Varkoi, T. (2013). "Safety as a process quality characteristic", International Conference on Software Process Improvement and Capability Determination, pp.1-12. 